\title{
AFECTOS, DESINTEGRACIÓN E INTIMIDADES AMENAZADAS
}

\author{
POR \\ ISABEL QuinTANA \\ UBA-CONICET
}

En las últimas décadas hemos asistido a debates provenientes de distintas disciplinas que han contribuido a la formulación de los diversos giros teóricos y que han tenido sus resonancias en el terreno de la teoría y la crítica literaria. El giro afectivo -más específicamente, el amoroso, que es el que particularmente nos convoca a la escritura de este trabajo, se ha nutrido de los aportes de la sociología, la historia, la ciencia política, la antropología, el psicoanálisis y la filosofía, entre otros. La renovación fundamental consistía en desarticular la antigua oposición entre la razón y los afectos o emociones. Así, cobra especial relieve el concepto de identidad pero también el de comunidad como modulaciones de la experiencia subjetiva ceñidas a prácticas individuales o comunitarias pero también a políticas de Estado (Athanasiou 5-16). Desde una matriz biopolítica, Agamben retoma dicha noción para analizar cómo la subjetividad es el campo experimental a través del cual se busca que el hombre se desprenda de aquellos atributos que lo hacen humano para lanzarlo a la intemperie de su pura animalidad, el homo sacer (Lo que queda de Auschwitz 148).

A su vez, Illouz plantea la idea de las "intimidades congeladas" (10-40). Es decir, así como la noción de poder planteada por Foucault y retomada por Butler produce y tiene efectos sobre la subjetividad, en la era del capitalismo (desde el mundo empresarial hasta los libros de autoayuda) las emociones se han convertido en una gran maquinaria que no solo no niega los afectos sino que los produce e interviene a través de diferentes formas de captación y cooptación que no necesariamente tienen la forma aparente de una represión sino que van de la mano de los manuales de psicología en donde se le da la palabra al otro y se lo escucha. La máquina antropológica tanto interviene sobre la vida como sobre los sentimientos dando lugar a prácticas amorosas o figuras del amor en donde los sujetos quedan atrapados. En este sentido, existe cierta literatura (corpus que analizaremos a continuación) que puja por desarticular, poner en evidencia, desmontar ese gran artificio. La palabra adquiere en estas estéticas una reflexión 
que conduce a lo que en términos de Rancière se denomina división de lo sensible (Partage 16-30; traducción mía). Son literaturas que buscan aniquilar los dispositivos discursivos sobre los que se asienta "una ideología de las emociones" dando lugar a otras subjetividades que no necesariamente supone una convivencia pacífica entre los personajes, sus afectos amorosos y el universo axiológico imperante.

La dimensión estética de lo sensible constituye el eje de una de las vertientes teóricas a partir de la cual reflexionamos sobre el amor. ${ }^{1}$ Para Rancière lo real y lo estético no son instancias que van separadas. Sin embargo, conservan modos de actuación diferenciados que permiten mantener la distancia crítica. Esta forma de actuación del arte es una manera de reflexionar sobre la dimensión de lo político como momento de quiebre que posibilita la reasignación de lugares y la reconfiguración de nuevas visibilidades (Espectador 77).

En el corpus a analizar: Museo de la revolución (2006) y Bahía Blanca (2011) de Martín Kohan, El aire (1992) de Sergio Chejfec e Impureza (2007) de Marcelo Cohen, los protagonistas están atrapados tanto por sus reflexiones a veces obsesivas como por su pasiones; relaciones de domesticación y dominio que ponen en evidencia las relaciones de poder y un régimen axiológico particular que delimitan y crean sus afectos. El ámbito público y el privado aparecen trabajados como una densa trama en donde ambos confluyen o se separan a partir del dispositivo amoroso, la militancia política, la precarización del estado neoliberal, la fuerte intervención estatal en el control de la vida ciudadana o, por el contrario, en medio de un espacio en donde la política se ha retirado mientras se asiste a una pura banalización del mundo.

PolíticA Y AFECTOS

Puede que todo eso dé la impresión de que estaba partido en dos, o en tres, o en cuatro. Ahora no sabe que fue de él. Ese desenlace, que ni siquiera es el de la muerte, sino el de la incógnita, puede que lo arrastre a la apariencia de lo compacto. Pero estaba tan partido como puede estarlo cualquiera, como lo están muchos, si es que no todos, incluso en aquel tiempo tan de vehemencias y organicidad.

Martín Kohan, Museo de la revolución ${ }^{2}$

1 He desarrollado más extensamente estas ideas junto a Nora Domínguez en "Sobre el pensamiento estético y político contemporáneo: la literatura hoy".

2 Agradezco a Martín Kohan el diálogo compartido en torno a sus novelas, cuestión que me ayudó en la escritura de este trabajo.

Revista Iberoamericana, Vol. LXXXII, Núm. 257, Octubre-Diciembre 2016, 775-792 ISSN 0034-9631 (Impreso) ISSN 2154-4794 (Electrónico) 
Algunos de los textos que vamos a analizar guardan una relación compleja con el mundo político, social y cultural de los años '90 (el "menemato"). ${ }^{3}$ De alguna forma, ellos plantean ¿cómo la literatura lee dicha época?, o ¿qué hace la literatura con los materiales que le ofrece el contexto neoliberal? En ese sentido, Museo de la revolución realiza un sinuoso movimiento temporal y geográfico para narrar desde el presente (los '90) una historia ocurrida veinte años atrás en un pueblo del interior argentino, cuyo historia se despliega en México. El eje que cruza y une (como también separa) ambas temporalidades es el testimonio que porta la voz y el cuerpo de una mujer: Norma Rossi. Ella encarna, a su vez, los atributos de la época actual (los '90) en donde los fundamentalismos ideológicos se han desvanecido mientras se asiste al mundo frívolo del consumo, pero ella es también un vestigio del pasado. Además, el cuerpo y la escritura funcionan en esta novela a modo de espejo, tal vez invertido, de la historia de Rubén Tesare, militante del ERP, y Marcelo, el escritor que en los '90 viaja al D.F. tras la búsqueda de un cuaderno de Tesare que posee Norma Rossi. En dicho cuaderno Tesare desarrolla una larga reflexión sobre la revolución a partir de los escritos de Marx, Lenin y, fundamentalmente, Trotsky. Y es justamente Norma, en aquella época denominada Fernanda Aguirre, la que sirve de carnada para que un grupo de tareas irrumpa en la tranquilidad de un hotel pueblerino de Córdoba y se lo lleve a Tesare. Ella ha sido una entregadora pero en la época actual dicha definición parece diluirse cuando antiguos militantes de izquierda se han reformado y conviven pacíficamente con el régimen de moda. Pero, por otro lado, no olvidemos que la historia de la novela se desarrolla en México, cuna de una de las revoluciones más importantes del siglo XX en Latinoamérica, pero también testigo de la institucionalización del partido revolucionario y su lenta degradación. La novela, entonces, que desarrolla en su interior la forma del ensayo, trabaja y entrelaza materiales de diversas procedencias: la idea de una subjetividad militante en los años ' 70 dentro de la izquierda argentina, la teoría de la revolución permanente desarrollada por Trotsky y, también, la revolución congelada en México. El Museo de la revolución se convierte así en un dispositivo que habilita la posibilidad de ingresar al museo para descomprimir una temporalidad paralizada e introducir el largo movimiento reflexivo de los escritos de Tesare que lleva a invocar los fantasmas (la traición a la revolución) pero también el espíritu de Marx (la promesa de la revolución). ${ }^{4}$

Como decíamos anteriormente, Norma Rossi articula entonces el pasaje de una época a otra pero también lleva en su propio cuerpo la escritura de otro cuaderno que

3 Época que comprendió la presidencia de Carlos Saúl Menem cuyo gobierno (1989-1995; 1995-1999) privatizó empresas nacionales de gran importancia y declaró el "punto final" a los juicios de los militares (iniciados durante el gobierno de Raúl Alfonsín, 1983-1989) involucrados en la tortura y desaparición de personas durante la dictadura militar (1976-1983).

4 Seguimos aquí las ideas desarrolladas por Derrida en Espectros de Marx.

Revista Iberoamericana, Vol. LXXXII, Núm. 257, Octubre-Diciembre 2016, 775-792 ISSN 0034-9631 (Impreso)

ISSN 2154-4794 (Electrónico) 
une la política con el ámbito de la intimidad. Y es ese cuaderno que Marcelo cree que en verdad existe, el que provoca la itinerancia de este personaje en torno a Norma quien no puede dejar de programar encuentros con él para leerle el cuaderno de las largas reflexiones teóricas sobre la revolución de Tesare. Y aquí la pregunta que surge es: ¿por quélee Norma Rossi?, ¿québusca tras esa lectura que por momentos parece desesperada? De alguna forma, lo que la novela articula aquí es una escena de lectura que provoca al mismo tiempo que retrasa el avance de la novela (y el encuentro amoroso entre Norma y Marcelo), ya que al poner en primer plano esas largas digresiones teóricas, la otra historia -la de la intimidad y subjetividad militante de Tesare, que es, en definitiva, la que le importa a Marcelo-, aparece entre los resquicios. Como plantea Coira:

Norma Rossi distribuye su tiempo con el narrador entre leerle largos fragmentos de los ensayos políticos escritos por Tesare con la narración oral del otro texto (que parece conocer de memoria) de carácter íntimo [...] Es como un trabajo práctico pensado por un formalista ruso para que los lectores contengan la ansiedad por la historia (a ver si tienen relaciones sexuales y cómo, qué pasa con ellos luego, etcétera) y sepan detenerse en el discurso aunque pueda aburrir a la mayoría todas esas reflexiones sobre el tiempo y la revolución. (80)

Sin embargo, a medida que avanza la lectura y se acrecienta la tensión de Marcelo por conseguir el otro cuaderno, se acelera también el final de la historia y la verdad que porta Norma en su cuerpo: los últimos momentos de Tesare en el hotel de Laguna Chica en un atardecer de provincia junto a Fernanda Aguirre (Norma Rossi) a fines de 1975. Y es así, entonces, que Marcelo recibe la más plena revelación a través del encuentro sexual con Norma de cómo fue el otro encuentro también sexual de esa mujer con Tesare hace veinte años atrás. De todos modos, la novela ha anticipado dicha relación en diversos pasajes a través de los detalles descritos por Norma. En definitiva, solamente alguien que estuvo en aquel lugar y tuvo intimidad con Tesare pudo construir tal relato y luego, en la actualización de dicha escena con Marcelo (cuando Norma decide por fin contar minuciosamente cómo ocurrió) explicar cómo y de qué forma fue ese encuentro con el militante desaparecido.

Lo interesante aquí, como el mismo Marcelo lo expresa, es que no hay odio hacia Norma. Tal vez porque el universo que ahora comparten es sumamente lejano y diferente al de los '70. La distancia entre Tesare y Marcelo es intransferible y el universo axiológico ha cambiado de signo. Así como las relaciones de poder conforman y producen a los sujetos, dentro del ámbito de las agrupaciones de izquierda de aquellas décadas la subjetividad militante suponía un apego a cierta moral extraña al exterior de la misma. De ese mundo, aunque de manera compleja, Norma es entonces un testimonio; un testimonio de otra zona de la subjetividad, la de los afectos. Es que entre los motivos que llevaron a Tesare a ese lejano pueblo con una misión determinada

Revista Iberoamericana, Vol. LXXXII, Núm. 257, Octubre-Diciembre 2016, 775-792 ISSN 0034-9631 (Impreso) 
a ejecutar - entregar un bolso-, existe una causa anterior de la cual debió dar pruebas de su fidelidad a la agrupación: la renuncia a tener como novia una mujer de otro movimiento guerrillero (montoneros) por cuestiones de seguridad. Tesare no sólo va a cumplir entonces una misión dictaminada por su dirección sino que también y, a través de ella, debe dar pruebas de su lealtad. Sin embargo, no es fiel a las instrucciones de su dirección, a saber, pasar especialmente desapercibido:

Se está metiendo en la cama con una chica que se llama Fernanda Aguirre, a la que acaba de conocer y de la que nada sabe. Si un nombre se le soltara, sin embargo, en mitad de estos aprontes, sería el de Gabriela, a quien nunca más verá, y no el de Fernanda, que es quien lo está besando ahora. Debajo de la otra cama que por el contrario luce quieta, espera, mientras tanto, un bolso. El bolso cuyo contenido llegando a las manos debidas, puede torcer el curso de los acontecimientos en un sentido o en otro. Y muy cerca de ese bolso, que está oculto, hay otro bolso, que no está oculto, un bolso de mano donde Tesare lleva siempre consigo el cuaderno con sus notas, ese cúmulo de páginas apuradas que sirve para entender que Tesare, además de la revolución, quería pensarla y quería escribirla. (113)

Es en ese contex to que él, quien, por otro lado, de acuerdo al pensamiento desplegado en sus escritos parece más cercano al universo intelectual que al de la acción, y que está bastante agobiado por las demandas que impone el partido, comete un error estratégico (irse al hotel con Fernanda, una desconocida), hecho que lo conducirá directamente a la tortura y la desaparición.

Si Norma porta en su cuerpo la escritura de una zona de la intimidad de Tesare, convirtiéndose así en un verdadero objeto de deseo para Marcelo, la misma se despliega en la literalidad de la puesta en escena (volver a repetir con Marcelo el acto sexual realizado hace veinte años con Tesare mientras lo va verbalizando detalladamente) pero también y, a través de ese acto, en la convocatoria de un fantasma del pasado: un militante de los ' 70 . A partir de allí, Tesare deja de ser una mera figura retórica de la literatura sobre dicha época para ingresar en el presente con una intensidad en donde se anudan y entran en conflicto la esfera afectiva y la de la praxis revolucionaria. En definitiva, el mundo de la lucha armada se regía por un régimen normativo propio que actuaba sobre la subjetividad militante conformándola.

De este modo, Museo de la revolución incorpora la escritura ensayística (cuyo marco es la novela que se narra) realizando, como Norma -portadora de la escritura de Tesare sobre su cuerpo-, un doble movimiento: volver hacia el pasado supone abrir la puerta por donde ingresan tanto los espectros (las traiciones, los campos de concentración; en definitiva, Stalin), como el espíritu de Marx (la promesa del

Revista Iberoamericana, Vol. LXXXII, Núm. 257, Octubre-Diciembre 2016, 775-792 ISSN 0034-9631 (Impreso)

ISSN 2154-4794 (Electrónico) 
socialismo, la idea de justicia). ${ }^{5} \mathrm{Y}$ es justamente en el cuaderno de Tesare donde se abre una amplia reflexión sobre la tradición -como documento de barbarie-, la potencia del presente - la posibilidad de la revolución-y el futuro; es decir, la reactualización permanente del legado revolucionario.

Así como en la amplia obra de Kohan el contexto histórico estaba presente ya sea como eje central de su narrativa o de manera tangencial, en su última novela Bahía Blanca, el escritor diseña otra estrategia que supone una suerte de repliegue al ámbito privado o íntimo de su personaje, de allí también la elección de la escritura de un diario que despliega el protagonista (Mario Novoa). La historia, entonces, se narra a partir de ese diario y el punto de vista aparece permanentemente filtrado por sus reflexiones sobre el ámbito exterior en donde acontece de forma banal la vida. También aquí, la trama se inicia con el desplazamiento del personaje a Bahía Blanca (en Museo de la revolución Tesare viajaba al interior, y Marcelo al D.F.), quien ha ganado una beca para realizar una investigación sobre Martínez Estrada (cuya obra dice desconocer). Pero el mundo académico e intelectual aparece completamente desacralizado, como parte de la maquinaria del empleo estatal. En definitiva, Mario Novoa utiliza el sistema académico con fines puramente personales, para tratar de escapar y olvidar un crimen por él cometido.

Como en Museo de la revolución, aquí también la historia se desarrolla en torno a un secreto que está atado al ámbito de lo íntimo -y aquí se puede pensar hasta qué punto en ambas novelas el desplazamiento al interior supone un ingreso a la interioridad de los personajes. En Bahía Blanca hay una zona de la intimidad que no aparecía desarrollada en la otra novela: el universo de las pasiones y obsesiones sentimentales que conduce a Novoa a no reconocer el deseo del otro (en este caso el de Patricia, su esposa):

Que me conoce [le dice Patricia a Novoa], repite otra vez, y se dio cuenta: se dio cuenta de que si ella me daba su respuesta (en este caso: que no me quiere, que no le parece que vaya a quererme y que no desea volver a intentarlo) en cualquier otra situación que no fuera la que estaba propiciando yo (y que por lo visto era ésta: los

\footnotetext{
En Espectros de Marx, Derrida plantea que el marxismo no ha muerto y que por lo tanto debe ser conjurado a través de un trabajo de duelo que supone desprenderse del espectro (Stalin) para recuperar el espíritu (la revolución). No se sabe si el fantasma da testimonio de un ser vivo pasado o de un ser vivo futuro. El comunismo es espectral, siempre está por venir y se distingue (como la democracia) de todo presente vivo como plenitud o presencia (121-25). En momentos de grandes crisis revolucionarias se evocan los espectros del pasado. Se trata de traer la muerte para inventar lo vivo rechazando la reproducción mecánica del espectro. Para ello, hay que olvidar sin olvidar: es decir olvidar lo suficiente como para recuperar el espíritu de la revolución -la justicia- sin hacer volver su espectro -el horror(130).
}

Revista Iberoamericana, Vol. LXXXII, Núm. 257, Octubre-Diciembre 2016, 775-792 ISSN 0034-9631 (Impreso) ISSN 2154-4794 (Electrónico) 
dos en Bahía Blanca), yo no me iba a conformar, no me iba a resignar, no iba a aceptar lo que me dijera. (269)

Si en Museo de la revolución habíamos planteado que la subjetividad militante se encontraba regida por una moral particular, en Bahía Blanca es el mundo de los afectos el que se sume a su propia moral. El protagonista de esta novela desarrolla determinados rasgos (apatía, indiferencia, ajenidad), ya presentes en otros personajes de las novelas de Kohan, que lo colocan en un estado de suspensión y repliegue durante la primera parte de la novela. Dicho repliegue se encuentra sujeto a una cuestión estratégica: permanecer anónimo y distanciado de la escena del crimen que ha cometido, el asesinato del nuevo esposo de Patricia. Novoa trata de olvidar y, tal vez, por eso se entrega a la repetición detallada de hechos cotidianos. En un punto la novela también se abre al relato policial, ya que es sobre los signos ausentes de los hechos (el móvil, el instrumento del asesinato) que el escritor crea el suspenso en el espacio asfixiante de una ciudad que porta una carga simbólica negativa (se dice que es la ciudad del aburrimiento, de la desesperanza en donde la iglesia y los militares ejercen dominio en la vida de sus habitantes). Sin embargo, esa disciplina que Novoa desarrolla no contiene la pulsión de contar todo (el relato del crimen) cuando se encuentra con un viejo amigo, Ernesto Sidi (enamorado en el pasado de Patricia).

Así, en ambas novelas, el secreto funciona como condensación de un sentido que sólo se dejará ver cuando los personajes que lo portan son increpados por una pregunta que los lleva a la confesión de una acción realizada que los coloca por fuera del ámbito jurídico (en un caso, en un tiempo en donde los servicios de inteligencia imponían una suspensión de la legalidad vigente; en el otro, en una zona de la intimidad que aparta al sujeto del mundo y lo empuja fuera de una interdicción primordial: "No matarás"). En una dimensión material Tesare y Novoa son también portadores de un mismo objeto que encubre sus respectivos secretos, el primero tiene que entregar un bolso a los compañeros (no se sabe qué contiene, probablemente armas), el segundo lleva en un bolso la "carterita" del muerto como coartada-que sospechen que el asesinato fue producto de un robo-. Lo material tiene también una potencia especial en la articulación de los personajes porque de alguna manera los coloca en una situación de excepción (ilegalidad), un mismo objeto, el bolso, que porta lo que se quiere ocultar y determina el devenir de Tesare y Novoa.

Finalmente, la pregunta (Marcelo le pregunta a Norma, Ernesto Sibi a Novoa) conduce a los portadores del secreto a decirlo todo de una vez, en ese punto ambas novelas abren un espacio que interrumpe una zona del relato al desajustarlo, al hacer ingresar a la narración lo no dicho hasta ese momento. No importa la distancia cronológica que separa la acción del acto de contar; lo cierto es que acción y pensamiento se ven afectados, quiebran una zona de la sensibilidad y dejan paso a la palabra. Una vez hecha la pregunta, los personajes no pueden dejar de expresarse y darle forma al relato de lo

Revista Iberoamericana, Vol. LXXXII, Núm. 257, Octubre-Diciembre 2016, 775-792 ISSN 0034-9631 (Impreso)

ISSN 2154-4794 (Electrónico) 
no dicho. Pero ese secreto no está vedado a causa de un sentimiento de culpabilidad, como dijimos antes, aquí los regímenes morales se encuentran trastocados. Si Museo de la revolución se inscribe en el contexto argentino de los ' 90 , era de la frivolización política y social en donde, tras la leyes de amnistía, los antiguos líderes y contrincantes revelan su verdadero rostro a partir del oportunismo ideológico que la época favorece (antiguos enemigos políticos se publicitan durante el gobierno de Menem como aliados intentando recolocarse políticamente de acuerdo a un contexto que favorece ese tipo de encuentros sobre la base de la necesidad del olvido de las atrocidades de la dictadura). Bahía Blanca, por su lado, muestra el repliegue al ámbito de lo íntimo, lugar donde los afectos escapan también a la órbita de las leyes jurídicas y las interdicciones morales. Los personajes se nutren así de una experiencia en donde se suspende la norma (Norma Rossi es quien posee esa palabra como nombre) para dar cabida a otra dimensión de la subjetividad: una hendidura en la racionalidad que no supone un desborde irracional sino la mostración de otra verdad del sujeto.

\section{DISGREGACIÓN Y PRECARIZACIÓN}

Las cartas, los silencios, la misma ausencia repetida de Benavente, surgiendo y multiplicándose a cada instante, significaban proyectiles lanzados contra su figura que, sin posibilidad alguna de elusión, no tenía otra alternativa que recibir: pruebas concretas eran el dolor, el vómito y las hemorragias.

Sergio Chejfec, El aire

En la novela de Chejfec, El aire, ciudad y amor, tema clásico de la literatura, como lo ha planteado Sarlo, reaparecen en un contexto enrarecido por la precarización laboral y social:

Novelas como las de [...] Chejfec muestran cómo una subjetividad y una ciudad se necesitan para narrar la crisis de la voluntad y del amor. Tema clásico de la modernidad. El fin de una relación arroja al que lo padece al espacio de la ciudad, sin itinerario, como si la ciudad ya no tuviera ningún orden sino el de la casualidad. De esta ciudad, Chejfec expone una visión de un futurismo pesimista: tugurios en los techos, niños que juntan vidrio para usarlo como una nueva forma del dinero, multitudes que no saben bien por qué hacen lo que hacen. (“Amores")

La novela (como en otras novelas suyas: El llamado de la especie, Boca de Lobo, entre otras) trabaja con los materiales literarios desde una perspectiva extrañada sobre la realidad (en el contexto de los '90): 
En la narrativa de Sergio Chejfec la ciudad y sus márgenes son espacios en donde transcurren las vidas de los personajes. Lugares que escenifican una suerte de posurbe, -especialmente en Boca de Lobo (2000)-envueltos, sugestivamente, de cierto substrato arcaico o premoderno -sobre todo en El llamado de la especie (1997)- que desatan y profundizan dicha turbación. La ciudad propiamente dicha se yergue de manera fantasmal, proliferando en sus bordes, en sus zonas residuales o en los antiguos cordones industriales. Y, por su lado, los habitantes de estos territorios se encuentran compenetrados en su realidad de una manera que no puede dejar de asombrar y, al mismo tiempo, alterar a los narradores de estas historias. (Quintana, "Peregrinajes"280)

Como señalábamos al comienzo del apartado anterior, nos interesa ver cómo la literatura lee dicha época. Si Kohan elige configurar una escena de lectura desde el presente para acercarse a ciertas zonas de la experiencia de un militante de los ' $70 \mathrm{y}$, desde allí, exhibir la precariedad ideológica de los '90; Chejfec configura un espacio en donde los cuerpos, la memoria y la materia padecen un proceso de desintegración que alude también a los " 90 pero de manera "oblicua" (termino utilizado por Kohan en una entrevista realizada a Sergio Chejfec): ${ }^{6}$

Donde habían vivido amigos y familiares ahora quedaban los árboles y alguna que otra pared. De manera literal, el campo avanzaba sobre Buenos Aires. De ese modo, había leído en algún lado, con la remisión de la ciudad el espacio, que era una categoría fundamental para la subsistencia de una memoria colectiva se estaba desvaneciendo en el medio del aire. (El aire 163-64)

Desde allí, se narra la propia desubjetivación de Barroso, el protagonista de este relato que ha sido abandonado por su mujer. Dicha desarticulación del personaje es la que determina el punto de vista de la narración que va tras los restos de una ciudad en retirada ante el avance del campo mientras se asiste al desarrollo de la "tugurización" en las azoteas (villas miserias verticales). El texto es un entramado de restos materiales y afectivos atravesado por la propia experiencia de abandono que sufre Barroso. Lo que predomina es la falta de espesor de los objetos y de los cuerpos. En sus largas caminatas por la ciudad que lo llevan a las zonas de frontera en donde se disuelve definitivamente la urbe, Barroso pierde su propia consistencia y, aunque intenta asirse a un sistema de cálculos que le permita, de alguna forma, calcular distancias y volúmenes, las magnitudes también van perdiendo su propia realidad.

6 En dicha entrevista Chejfec plantea la relación entre la realidad y la literatura: "La literatura en realidad arma una escena social, con lazos más o menos indicativos respecto de lo conocido; pero es una escena compuesta con materiales ajenos a lo social, es una composición literaria, de manera que el equilibrio delicado o burdo del resultado no dependerá de las convicciones del escritor" ("No me interesa convencer a nadie").

Revista Iberoamericana, Vol. LXXXII, Núm. 257, Octubre-Diciembre 2016, 775-792 ISSN 0034-9631 (Impreso)

ISSN 2154-4794 (Electrónico) 
El texto, sin embargo, gana intensidad al imponerse, paradójicamente, el relato de cierto desvanecimiento del mundo o de un mundo antiguo en retirada, y abre otra zona de la experiencia que es estrictamente literaria: el campo y las letras. Así, mientras la planicie gana terreno sobre viejas edificaciones y las villas miserias se repliegan a las terrazas de los departamentos, Barroso debe traducir constantemente el lenguaje arcaico utilizado por él (que él mismo denomina “el lenguaje de la niñez") a las nuevas formas de decir. Ese trabajo fuerza su pensamiento, sus largos monólogos interiores que lo llevan a reparar en minúsculos detalles y que lo confronta con otro lenguaje, el del periódico que, paradójicamente, desarrolla un análisis a destiempo: es decir, vaticina un futuro que ya es presente y que Barroso lo ha visto en sus largos paseos. Pero también, diario y ciudad se convierten en propaganda de slogans nacionalistas que recuperan el espacio rural frente a la decadencia de la ciudad. La literatura (nacional), entonces, parece volver a su punto cero cuando la llanura era su límite y, al mismo tiempo, su condición de posibilidad.

En una ciudad tugurizada y en proceso de extinción, el lenguaje sufre también cierta desarticulación, el campo amenaza el lenguaje de la comunidad e impone con prepotencia su propio discurso. Barroso, a su vez, no pudiendo confrontar su propia pérdida amorosa, se sume en una suspensión melancólica que aniquila su propio cuerpo. Las cartas - otra figura literaria de la intimidad-que Benavente, su esposa, le va dejando bajo la puerta de su casa, son ambiguas con respecto a su abandono pero también determinan la estructura de la espera y la sumisión en la melancolía (no hay duelo porque todavía no hay aceptación de la pérdida), aunque son implacables en su contenido (le ordena que no la siga al mismo tiempo que le anuncia su próximo paradero en Uruguay). Mientras tanto, Barroso -barre, se torna inconsistente, es barro-, se va vaciando de todo contenido que no sea otro que lo lleve a recordar a Benavente o a pensar en la ciudad (las dos en una vehemente retirada), su cuerpo sufre su propio proceso de descomposición ante la llegada de la enfermedad. Barroso es una figura desfigurada que comienza a sentir por zonas, a desintegrarse como totalidad orgánica para abrirse a ciertas intensidades que lo acosan a través del dolor y el derrame: sangre, vómito, diarrea. El cuerpo es entonces un campo de fuerzas que se compone por niveles o umbrales, un cuerpo sin órganos. Y es entonces a partir de esta nueva realidad del sujeto que el pensamiento se une a la experiencia sensible. Si Barroso, además, no hace otra cosa que pensar (en Benavente, en la ciudad, en las palabras, en los volúmenes y los espacios) es porque determinados signos que provienen del exterior han comenzado a hacerse visibles. Es justamente a partir de la partida de Benavente que repara en la opacidad de la ciudad y el deterioro de su población y la incluye dentro de su propia experiencia produciéndose así una nueva división de lo sensible. Aquello antes no visto irrumpe forzando a desacomodar el paisaje conocido: 
También había familias enteras que trataban de rescatar algo de valor de los contenedores, o madres con sus niños que hacían colas a un costado de las panaderías o restaurantes aguardando, si no las sobras de los alimentos, en todo caso el traslado de la basura hasta la calle. Presumiblemente por falta de hábito, para poder hacerse con unas cuantas botellas Barroso acabaría caminando el triple que cualquier otra persona experimentada en la recolección. (165)

Pensar comienza con la diferencia, diría Deleuze, cuando frente a un nuevo signo el punto de vista tiene que cambiar, es decir, es afectado. "Lo que fuerza a pensar es el signo. El signo es el objeto de un encuentro; pero es precisamente la contingencia del encuentro lo que garantiza la necesidad de lo que da qué pensar" (Proust 180). ${ }^{7} \mathrm{De}$ modo que un encuentro con zonas del exterior no conocidas y con la otredad del sujeto amado, supone una redefinición del afecto en tanto signo que fuerza al pensamiento y lo pone en relación con otras fuerzas (Zouravichvili 57-58).

Si en Museo de la revolución la introyección disciplinaria (en el contexto general de la suspensión de la ley) articulaba una subjetividad militante frente a la amenaza militar y parapolicial, en El aire otra vez el clima se ha enrarecido (en varios pasajes del relato se alude al aire) pero ahora es la precariedad económica y emocional la que afecta a una comunidad en proceso de extinción. Dicha desaparición se traduce en la pérdida de hábitos; es decir, de una cierta identidad que en otras épocas caracterizaba a los pobladores: no son capaces de construir sus propias casas, juegan mal al fútbol $\mathrm{y}$, sobre todo, su lenguaje también se ha precarizado. Frente a la pobreza crean una economía residual que se alimenta de los desechos que ellos mismos producen: fundamentalmente el vidrio ha reemplazado la falta de dinero. Como en otros textos de Chejfec, aparece así una comunidad que apunta a la propia etimología de la palabra, ya que lo que une a sus integrantes, como plantea Esposito en Communitas, no es lo que tienen en común sino aquello de lo que carecen: "Communitas es el conjunto de personas a las que une no una propiedad, sino justamente un deber o una deuda [...] Conjunto de personas unidas no por un 'más', sino por un 'menos', una falta [...] una modalidad carencial para quien está áfectado" (30).

La anomalía parece ser la forma de la experiencia de un mundo en la agonía de su lenta extinción. El relato de Chejfec, entonces, sería un ejercicio en donde la escritura le da forma a lo que se desvanece, se plantea el desafío de narrar no la invención de un mundo o su destrucción sino esa suerte de límite o umbral donde las formas y afectos se descomponen.

\footnotetext{
“¿Cuál es la estructura (fábrica) de un cuerpo? ¿Qué es lo que puede un cuerpo? La estructura de un cuerpo es la composición de su relación. Lo que puede un cuerpo es la naturaleza y los límites de su poder de ser afectado" (Deleuze, Spinoza 208).
}

Revista Iberoamericana, Vol. LXXXII, Núm. 257, Octubre-Diciembre 2016, 775-792 ISSN 0034-9631 (Impreso) 
INTIMIDAD Y MEMORIA

\begin{abstract}
Se avecinaba un cambio. Habia un derecho imposible de vetarle a nadie, y era el derecho a buscar el alivio del sufrimiento en la intimidad. Desde la explanada de la Gasomel entre el tarareo cibernético de los robots inyectores, Neuco veía agonizar un mundo violento y roñoso. Pero no iba a morir, ese mundo. La agonía era su forma de durar. Vivir de veras, sólo vivía lo íntimo. Él estaba solo. Estaba rodeado de fuego y de velocidad. Pero se le iban apagando los recuerdos asquerosos. Claro que con la extinción de la memoria se quedaba también sin horizonte y todo el provenir se le reducia a la aparición de un acontecimiento.
\end{abstract}

Marcelo Cohen, Impureza

En la obra de Marcelo Cohen (heredero, entre otros, de la obra de Philip K. Dick) asistimos a la creación de mundos futuros que se realimentan constantemente tanto de los avances como de los desechos tecnológicos -su literatura se nutre de cierta tradición de la ciencia ficción y de lo fantástico-. En un gesto similar al de Chejfec, se trata de novelas que trabajan con elementos del futuro exacerbando aspectos actuales (el presente de los relatos): el trastocamiento del lenguaje, la proliferación de voces, la deriva de subjetividades solitarias, la reducción de los espacios habitables, la precariedad económica y el dominio de las imágenes. Frente a los materiales crudos que el mundo ofrece se crean ficciones que trabajan zonas de la intimidad sobre las que el Estado interviene a través de diferentes agentes o por medio de la creación de una panconciencia - un circuito en donde se puede conectar al pensamiento de los otros pero también perderse en sus laberintos-.

Pero con su novela Impureza, publicada en 2007, el futuro ya se ha instalado (como se dice en distintos pasajes de dicha obra, y como aparece también de alguna manera en El aire). Mientras en El fin de lo mismo o Los acuáticos (narraciones escritas durante el menemato) la escritura era un ensayo de anticipación en donde elementos de la realidad se trastocaban al ingresar en escenarios futuristas, en Impureza se trabaja justamente bajo la premisa de lo impuro para mostrar su espesor y su dominio en el mundo real: el realismo impuro, al que se refiere el propio Cohen en sus ensayos (;Realmente fantástico! yotros ensayos) se compone de la heterogeneidad de elementos ensamblados donde lo arcaico, lo marginal y lo tecnológico se acoplan en una convivencia siempre tensionada por las diversas demandas de una comunidad al borde de lo social:

Hay minúsculos terrenos con sus casas inconclusas en el medio, hileras de viviendas

Revista Iberoamericana, Vol. LXXXII, Núm. 257, Octubre-Diciembre 2016, 775-792 ISSN 0034-9631 (Impreso)

ISSN 2154-4794 (Electrónico) 
adosadas, un centro comercial de insumos y baratijas, un pantallator de historias relámpago, un quiosco de la organización Vecinos Sin Máscaras, templos sectarios de policarbonato y salones bailables de chapa coloreada, una laguna con sus viejos pescando bagres mecánicos y su festón de aromos, un baldío pisoteado donde no crece ni la cizaña y, como un bagaje de residuos útiles en un armario mohoso, la maraña de cuasicas, estriada de barros eternos que los lugareños llaman Lafiera. (7)

Se trata de un trabajo sobre las palabras que redefine el trabajo literario (y que va más allá de la especificidad y la puesta en abismo) y busca romper la separación entre lo inteligible y lo sensible. En esta línea deleuzeana la obra de Cohen se acerca al planteamiento de Rancière: la experiencia estética es esa dimensión en donde confluyen ideas y sensaciones democratizando el campo de lo visual y el de las palabras, abriendo la literatura a voces y subjetividades impuras. El tango, la cumbia, el hip-hop, el rap, el lenguaje de los medios de comunicación performan las vivencias de los desocupados, marginales o desamparados en el mundo de la alta tecnología. Así, Cohen ha creado un vocabulario que ya es propio de su narrativa: flaycoches, pantallator (televisión), robots inyectores o robotinas, tranviliano (tren), Gasomel (estación se servicio) que se actualizan en cada nuevo relato mientras se agregan nuevos términos: cuasicas (casas de las villas miserias), templos sectarios, melonches y merigüeles (suerte de cumbias villeras), los impuros (trabajadores, desocupados, ladrones, homeless, drogadictos, religiosos, músicos populares, etc.).

Impureza es también, como lo es El aire, un texto que cuenta la historia de una pérdida (Verdey Maranzic, la novia de Neuco -ex-obrera, activista y bailantera-, ha muerto en un accidente de tránsito) y de la posibilidad/imposibilidad del duelo. Pero, si en El aire el mundo se articula (o desarticula) a partir de una desintegración (de la lengua, las costumbres, la arquitectura de la ciudad) que atraviesa la propia experiencia subjetiva del protagonista, en Impureza el planteamiento es otro: ya no se trata de la vivencia de un borramiento de los contornos definidos entre las palabras y las cosas sino de que esa suerte de enrarecimiento del mundo se presenta como una hibridez que puede tanto potenciar el uso del lenguaje como también hacer más evidente los ideologemas que conforma. El tango (otro híbrido), que ocupa largos parlamentos en la nouvelle y del que se nutre Neuco por un tiempo, se le revelará finalmente a éste como una lengua del pasado que es engañosa en cuanto a la plasmación de un ethos que crea un mito en torno a la revancha, cuestión emulada por Nígolo, un amigo tanguero quien finalmente se le revela como un estafador ideológico (y aquí no podemos dejar de pensar en el uso que Borges ha hecho precisamente de ese ethos en su relectura del tango y la gauchesca). ${ }^{8}$ Pero lo importante aquí es la idea de un movimiento continuo,

\footnotetext{
"Borges como escritor es excepcional pero no así la materia de la que se nutren sus cuentos (la violencia).
} Sin embargo, sí es novedoso el tratamiento que de ello hace a partir de una problemática bien definida:

Revista Iberoamericana, Vol. LXXXII, Núm. 257, Octubre-Diciembre 2016, 775-792 
de una suerte de musicalidad que es interna a algunos de los personajes (tangueros, cantantes de cumbias, la bailarina Verdey) y que los hace cambiar de signo ("el juego con los estereotipos simula posicionar personajes fijos, hasta que algo sucede y viran su propuesta", dice Mendoça).

El texto de Cohen, escrito a modo de fragmentos encabezados por un título, tiene a la memoria y a la intimidad (dos de los fragmentos que llevan tales nombres) como una zona de la experiencia subjetiva en donde, como mencionábamos anteriormente, se disuelve lo sensible y lo inteligible. Neuco, personaje habitado por ideas que determinan su estado emocional y su relación con el mundo (como también le sucedía a Barroso en El aire) va tramando con sus largos monólogos interiores (un modo de enunciación que se aproxima al ámbito de lo íntimo) dicha experiencia frente a un narrador que actúa como una suerte de panóptico superponiéndose a su voz. El cuerpo de Neuco sufre y, por lo tanto, se enferma (igual que Barroso). Frente a la irradiación constante de circuitos que se incrustan en la memoria de la gente (sistema llamado mnádex) y las drogas de uso masivo que sirven, fundamentalmente, para olvidar (tal vez porque hay una "sobrecarga de memoria" y existe un sector de la comunidad empecinado en cuidarla), Neuco, como también Verdey cuando está viva, lucha por preservar su intimidad y el propio recuerdo de su novia. La biopolítica es la gran figura de este futuro ya presente que busca controlar la vida pero también la memoria de una comunidad sometida por el deseo de consumo: intervenir sobre el cuerpo a través del suministro de psicofármacos y el uso de la tecnología tiene efectos sobre la vida y el recuerdo de los personajes. explicar. De este modo, la nouvelle exhibe su dispositivo compositivo: dispersión, incertidumbre y potencia creadora, a partir de la proliferación de palabras, los mensajes televisivos, las letras de las canciones que se propagan en la calle -especialmente las de Abran "Chita" Baienas, autor de melonches y merigüeles, antiguo amigo de fechorías de Neuco-quien también propaga la revancha pero a nivel social ("literatura del resentimiento", canciones que son una mezcla de las canciones de Rodrigo, Juan Luis Guerra y Eminem). De allí que Neuco viva sumido en la desconfianza y no pueda dejar de consultar una suerte de diccionario llamado Casos y cosas del idioma (que se lo ha regalado otro estafador, un profesor de neurociencia creador de la frecuencia mnádex) para reordenar los signos y encontrarles sentidos: "La sospecha de una conexión extraña entre cosas y palabras, incluso de un uso fetichizado

Borges encarnaría, según Sarlo en La pasión y la excepción, el conflicto propio de la modernidad, un sujeto que mira melancólicamente un pasado en el que virtud y coraje eran términos que se suponían mutuamente en función de un ethos. Esa suerte de culto a la violencia se funda en una ética que se define a partir de una serie de rituales en los que la gesticulación y la palabra acompañan a la acción. Es una manera de ordenar una violencia arcana, de darle sentido, dice Sarlo, de inscribirla en una trama de significación, y esto es justamente lo que fascina (y repele) a Borges y que, en definitiva, no es más que un programa estético" (Quintana, "Memoria" 70).

Revista Iberoamericana, Vol. LXXXII, Núm. 257, Octubre-Diciembre 2016, 775-792 ISSN 0034-9631 (Impreso) 
de ambas, le confiere al protagonista un estado de irritabilidad liberadora. Su paranoia es productiva, su potencia desmasificante" (Mendoça).

Pero también Neuco se empeña en preservar su recuerdo de Verdey frente a la arquitectura dudosa de la ciudad que cobija la forma de un mito. A través del santuario, hecho de cintas bailarinas, pantallas, luces y música, en honor a la memoria de Verdey y financiado por el cantante "Chita" Baienas, la presencia virtual de la activista y bailarina (suerte de nueva "Gilda") se presenta desmesuradamente, actuando, a la vez, como articuladora/desarticuladora (por saturación) de la memoria. Y es justamente a partir de esta deriva de la bailarina que el mito comienza a funcionar (la gente le rinde culto, se afirman sus poderes sanadores, etc.).

De este modo, el campo diferenciado de lo sensible y de lo inteligible se desvanece ante el paisaje como acontecimiento de una experiencia en donde se anudan las creencias, las palabras y la materialidad del mundo. La topografía del mundo se convierte en una zona de indiferenciación en donde la mente parece proyectar sus propias geometrías abrevando de los abundantes materiales que proliferan en el exterior: "El paisaje es chato pero cautivante como la vasta proyección en plano de un cerebro que sueña" (7).

Neuco, a su vez, procurará encontrar a la bailarina en otra manifestación espacial (y en movimiento, esencia de Verdey): "Su lenguaje es corporal. Es una luchadora social, baila para cortar las calles, baila ante las cámaras de los noticieros, baila para cocinar. Entre las palabras y el movimiento se construye la intimidad, que no es un simple robo o copia de la intimidad burguesa" (Jurovietzky 80).

Frente a esa exuberancia no figurativa de Verdey (no hay figuras ni rostros de ella, así lo ha decidido "Chita") Neuco, como Barroso (y también Novoa) intenta crear un espacio diferenciado para el recuerdo de su mujer. Pero mientras en Barroso intimidad y exterior confluyen en un proceso de desintegración, y Novoa en Bahía Blanca se encuentra anclado a su pasión por Patricia (cuando en la segunda parte de la novela la encuentra no puede reconocer el definitivo corte establecido por ella), Neuco, por su lado, se va replegando cada vez más al espacio de su intimidad y es en algún sentido, una conciencia muda que busca imponerse al consumo de drogas para el olvido, a las incrustaciones sobre la memoria del mnadex y al ritual creado en torno a su mujer en donde cada uno proyecta sobre la bailarina sus propias alucinaciones. Neuco intenta acercarse a ella a través del recuerdo (y el olvido) de detalles del pasado hecho de palabras, frases, figuras, emociones y en ese vaivén la verdad del amor nunca es algo evidente, su forma es cambiante y escurridiza, como las palabras: "La vida de amor produce acoples de palabras y vivencias" (Jurovietzky 80).

En estas tres novelas, la figura femenina tiene la fuerza articuladora de los deseos del otro pero también la potencia de su destrucción cuando ellas abandonan a sus parejas o mueren. Lo interesante aquí no es la reescritura de una típica trama amorosa que también puede funcionar al revés (cuando las mujeres son, a su vez, abandonadas) sino el trabajo que estos textos exhiben en torno a uno de los grandes temas de la literatura:

Revista Iberoamericana, Vol. LXXXII, Núm. 257, Octubre-Diciembre 2016, 775-792 ISSN 0034-9631 (Impreso)

ISSN 2154-4794 (Electrónico) 
el Yo recomendaría que se haga referencia al amor desde el principio en tanto afecto que se va a analizar, de esta forma aparece por primera vez al final, lo mismo con la figura femenina del amor. Para ello, como decíamos al comienzo, construyen diálogos complejos con la época, incorporan diseccionando y recreando materiales que provienen del mundo actual, indagan en la zona de la intimidad descongelando diferencias entre lo emocional y lo intelectual. Como vimos, los personajes desarrollan al mismo tiempo una dimensión subjetiva en donde los afectos no se separan del pensamiento; lo sensible e inteligible se encuentran atados a la forma en que se aproximan al mundo y al sujeto amado. Los cuerpos se enferman, se desestabilizan emocional e intelectualmente a partir de una puja con el entorno y la desaparición del personaje femenino. Cuerpo y mente conforman una matriz por donde se percibe un mundo que los afecta: sienten y especulan, aman y razonan, construyen una percepción de lo real mediada por ambas instancias que finalmente conforman una misma dimensión: no sienten y luego piensan, sino que pensar ya es una forma de sentido. Pero, además, cada uno de estos autores construye desde su estilo bien diferenciado, un diseño del mundo en donde confluyen: un uso particular de la palabra, el ingreso de la política y una democratización de la visibilidad en el sentido planteado por Rancière (cuestión desarrollada al comienzo de este trabajo).

\section{BiBLIOGRAFÍA}

Agamben, Giorgio. Lo abierto. Buenos Aires: Adriana Hidalgo, 2006. La potencia del pensamiento. Buenos Aires: Adriana Hidalgo, 2007.

Lo que queda de Auschwitz. El archivo y el testigo. Homo Sacer III. Buenos Aires: Pre-Textos, 2002.

Athanasiou, Athena, Pothiti Hantzaroula y Kostas Yannakopoulos. "Towards a New Epistemology: The 'Affective Turn'." Historein 8 (2008): 5-16.

Butler, Judith. Mecanismos psíquicos del poder. Teorías sobre la sujeción. Valencia: Cátedra, 1997.

Chejfec, Sergio. El aire. Buenos Aires: Alfaguara, 1992.

"No me interesa convencer a nadie". Entrevista a Sergio Chejfec realizada por Martín Kohan. Revista de Cultura N (septiembre 2005). <Clarin.com/suplementos/ cultura/ultimo/index.html>.

Cohen, Marcelo. Impureza. Buenos Aires: Norma, 2007. ¡Realmente fantástico! y otros ensayos. Buenos Aires: Norma, 2003.

Coira, María. "Memoria y trauma en tres novelas de Martín Kohan". Escenas interrumpidas II. Imágenes del fracaso, utopías y mitos de origen en la literatura nacional. María Coira, Rosalía Baltar y Carola Hermida, comps. La Plata: Katatay, 2012. 
Copjec, Joan. Imaginemos que la mujer no existe. Ética y sublimación. Buenos Aires: F.C.E., 2006.

Deleuze, Gilles. Diferencia y repetición. Buenos Aires: Amorrortu, 2002. Proust y los signos. Barcelona: Anagrama, 1995. Spinoza y el problema de la expresión. Barcelona: Atajos, 1996.

Derrida, Jacques. Espectros de Marx. Madrid: Trotta, 1995.

Esposito, Roberto. Bíos. Biopolítica y filosofía. Buenos Aires: Amorrortu, 2006. Communitas. Origen y destino de la comunidad. Buenos Aires: Amorrortu, 2003. Immunitas. Protección y negación de la vida. Buenos Aires: Amorrortu, 2005.

Foucault, Michel. Nacimiento de la biopolítica. Buenos Aires: F.C.E., 2007. Seguridad, territorio, población. Buenos Aires: F.C.E., 2006.

Illouz, Eva. Intimidades congeladas. Las emociones en el capitalismo. Buenos Aires: Katz, 2007.

Jurovietzky, Silvia. "La perseverancia de los cuerpos". Zama 2 (2010): 69-80.

Kohan, Martín. Bahía Blanca. Buenos Aires: Anagrama, 2011.

Museo de la revolución. Buenos Aires: Mondadori, 2006.

LaCapra, Dominick. Escribir la historia, escribir el trauma. Buenos Aires: Nueva Visión, 2005.

Historia en tránsito. Experiencia, identidad, teoría crítica. Buenos Aires: F.C.E., 2006.

Mendoça, Inés de. "Lengas, letras, palabras y cosas". El interpretador libros. 22 marzo 2009. < http:// elinterpretador.files.wordpress.com>. 14 sept. 2014.

Negroni, María. Galería fantástica.Buenos Aires: Siglo XXI, 2009.

Quintana, Isabel. "Memoria, cultura y violencia: posturas, diálogos, debates". El despliegue. De pasados y de futuros en la literatura latinoamericana. Noé Jitrik, comp. Buenos Aires: NJ Editores, 2008.

"Peregrinajes en la ciudad y sus fronteras: el deseo de comunidad en la obra de Sergio Chejfec". Ciudades translocales: espacios, flujo, representación. Perspectivas desde las Américas. Marcial Godoy Anativia y Rossana Reguillo comps. México-Nueva York: Instituto Tecnológico y de Estudios Superiores de Occidente y Social Science Research Council, 2005.

"Los planetas de Sergio Chejfec: vacilaciones de la memoria". Literatura argentina siglo XX. Tomo VII. David Viñas, dir. Rocco Carbone y Ana Ojeda comps. Buenos Aires: Paradiso, 2010.

y Nora Domínguez. "Sobre el pensamiento estético y político contemporáneo: la literatura hoy". Revista de Filología y Literatura Hispánica Dr. Amado Alonso. Universidad de Buenos Aires, Año XLII (2010): 275-94.

Rancière, Jacques. El espectador emancipado. Buenos Aires: Manantial, 2010. La palabra muda. Buenos Aires: Eterna Cadencia, 2009.

Le partage du sensible. Esthétique et politique. París: La Fabrique, 2000.

Revista Iberoamericana, Vol. LXXXII, Núm. 257, Octubre-Diciembre 2016, 775-792 ISSN 0034-9631 (Impreso) ISSN 2154-4794 (Electrónico) 
Politica de la literatura. Buenos Aires: Libros del Zorzal, 2011.

Rüsen, Jörn. "Emotional Forces in Historical Thinking: Some Metahistorical Reflections and the Case of Mourning". Historein 8 (2008): 41-53.

Sarlo, Beatriz. "Amores de ciudad". <www.perfil.com.contenidos/noticia>. 29 dic. 2008. La pasión y la excepción. Eva, Borges y el asesinato de Aramburu. Buenos Aires: Siglo XXI, 2003.

Tiempo pasado. Cultura de la memoria y giro subjetivo. Una discusión. Buenos Aires: Siglo XXI Editores Argentina, 2005.

Sibilia, Paula. La intimidad como espectáculo. Buenos Aires: F.C.E., 2008.

Zouravichvili, Francois. Unafilosofía del acontecimiento. Buenos Aire:Amorrortu, 2004. 